\title{
Utilization of Karangsong Beach as A Learning Resources Based on Local Wisdom in Improving Understanding of The Concept Students of Primary Teacher Education
}

\section{Pemanfaatan Pantai Karangsong sebagai Sumber Belajar Berbasis Kearifan Lokal dalam Meningkatkan Pemahaman Konsep Mahasiswa Pendidikan Guru Sekolah Dasar}

\author{
Kiki Fatkhiyani (*)
}

Sekolah Tinggi Keguruan dan Ilmu Pendidikan Nahdlatul Ulama Indramayu Jl. Raya Kaplongan No. 28 Kecamatan Karangampel Kabupaten Indramayu Jawa Barat

Dadang Suhada

Sekolah Tinggi Keguruan dan Ilmu Pendidikan Nahdlatul Ulama Indramayu Jl. Raya Kaplongan No. 28 Kecamatan Karangampel Kabupaten Indramayu Jawa Barat

\begin{abstract}
Received: October 24, 2018 This research was conducted to improve the understanding of the concept Revised: November 19, 2018 of PGSD students STKIP NU Indramayu by utilizing the Karangsong Accepted: November 19, 2018 beach as a learning resource based on local wisdom. The research method used is mixed method research or sequential explanatory strategy, which is a strategy that is applied by collecting and analyzing quantitative data in the first stage. In this study, data collection and analysis increase understanding of the concept of living things and their environment after being treated, followed by collecting and analyzing qualitative data in the second stage, namely revealing obstacles and solutions to students in utilizing the Karangsong beach as a learning resource based on local wisdom. The research subjects were PGSD students at STKIP NU Indramayu who attended the basic concepts of biology in elementary school. The utilization of Karangsong beach as a learning resource based on local wisdom can improve students' understanding of concepts as evidenced by the acquisition of $\mathrm{N}$-Gain values of 0.81 in the high category. As for the constraints and obstacles faced by students revealed through interviews. Based on the results of interviews, external factors are more than internal factors. The lack of application of the right learning model is one of the inhibiting factors in this study. This has caused learning goals cannot be achieved optimally

Keywords: Karangsong Beach, Learning Resources, Local Wisdom.
\end{abstract}

(*) Corresponding Author: $\quad$ fatkhiyani@gmail.com

How to Cite: Fatkhiyani, K, \& Suhada, D. (2018). The effect of utilization of karangsong beach as a learning resources based on local wisdom in improving understanding of the concept students of primary teacher education. Formatif: Jurnal Ilmiah Pendidikan MIPA, $8 \quad$ (3): 185-192. http://dx.doi.org/10.30998/formatif.v8i3.2930

\section{PENDAHULUAN}

Kegiatan belajar yang ideal berlangsung dalam berbagai interaksi belajar dan dibantu dengan berbagai macam alat bantu belajar atau sumber-sumber belajar. 
Penggunaan sumber-sumber belajar sangat penting dan relevan, mengingat pemanfaatan sumber-sumber belajar tersebut sangat membantu dalam memahami materi pelajaran yang disampaikan. Di sisi lain, pembelajaran juga harus berjalan dalam atmosfer yang bersahabat, menyenangkan, dan memenuhi kebutuhan penting peserta didik dalam proses pembelajaran (Leonard, 2018).

Konsep dasar biologi merupakan mata kuliah keahlian program studi yang dipelajari oleh mahasiswa Pendidikan Guru Sekolah Dasar (PGSD) di STKIP NU Indramayu. Mata kuliah ini bertujuan untuk memberikan pemahaman yang lebih luas tentang prinsip-prinsip dasar Biologi sebagai pendalaman wawasan pengetahuan dan pembelajaran IPA di Sekolah Dasar. Lingkup bahasan meliputi Sel Sebagai Satuan Terkecil Makhluk Hidup, Keanekaragaman Makhluk Hidup, Berbagai Fungsi pada Hewan, Berbagai Fungsi pada Tumbuhan, Makhluk Hidup dan Lingkungan, serta Kependudukan dan Pemeliharaan Kesehatan. Agar mahasiswa mampu mempelajari konsep Makhluk Hidup dan Lingkungan dengan baik, maka diperlukan metode dan sumber pembelajaran yang tepat. Tujuan pembelajaran yang dirumuskan difokuskan pada pembelajaran menggunakan observasi lingkungan bukan hanya dengan metode ceramah. Kombinasi metode observasi, eksperimen, dan diskusi akan melatih mahasiswa untuk dapat memotret adanya keanekaragaman hayati secara utuh

Menurut Prasetyo (2013) pendidikan berbasis keunggulan lokal (PBKL) merupakan usaha sadar yang terencana melalui penggalian dan pemanfaatan potensi daerah setempat secara arif dalam upaya mewujudkan suasana belajar dan proses pembelajaran, agar mahasiswa aktif mengembangkan potensi dirinya untuk memiliki keahlian, pengetahuan, dan sikap dalam upaya ikut serta membangun bangsa dan negara. Dengan kata lain, pembelajaran yang diselenggarakan disesuaikan dengan kebutuhan daerah, dengan memanfaatkan berbagai sumber daya alam, sumber daya manusia, geografis, budaya, historis, dan potensi daerah lainnya yang bermanfaat dalam proses pengembangan kompetensi sesuai dengan potensi, bakat, dan minat siswa.

Pantai Karangsong adalah salah satu obyek wisata yang menyuguhkan panorama alam ekosistem. Pantai Karangsong terletak di Desa Karangsong, Kecamatan Indramayu, Kabupaten Indramayu. Pantai ini juga dikenal sebagai pantai nelayan dengan kegiatan mulai dari pembuatan kapal, mencari ikan, tempat pelelangan ikan, hingga tempat berlabuhnya para kapal nelayan untuk menurunkan hasil tangkapan lautnya. Kawasan ini baru diresmikan sebagai Pusat Pembelajaran Keanekaragaman Hayati, Arboretum Mangrove Pertamina pada 10 Desember 2016 oleh Menteri Lingkungan Hidup dan Kehutanan. Oleh karena Pantai Karangsong berlokasi di Indramayu dan memanfaatkan segala potensi yang ada di dalamnya, maka bisa dikatakan hutan mangrove Pantai Karangsong ini merupakan sumber belajar berbasis kearifan lokal. Dengan adanya Pantai Karangsong ini menjadikan Kabupaten Indramayu memiliki kekhasan tersendiri yang tentunya dapat memberikan dampak positif pada sektor lain.

Berdasarkan hasil survei di lapangan pada 2017, pemanfaatan Pantai Karangsong sebagai sumber belajar masih belum dioptimalkan. Hal ini dibuktikan dengan hasil wawancara singkat dengan pengunjung. Hasilnya menunjukkan bahwa 12 dari 30 pengunjung, datang hanya sekadar menikmati pemandangan dan suasana alam yang tenang. Tanpa diketahui di dalamnya banyak yang dapat dijadikan sebagai sumber dan bahan pembelajaran, sehingga perlu kiranya sosialisasi yang maksimal tentang keberadaan Pantai Karangsong sebagai sumber belajar berbasis kearifan lokal.

Berdasarkan hasil wawancara dengan mahasiswa STKIP NU Indramayu, ditemukan adanya beberapa kendala dalam mempelajari mata kuliah Konsep Dasar Biologi di antaranya adalah pembelajaran yang dilakukan masih bersifat konseptual dengan luasnya cakupan materi yang harus dikuasai serta terbatasnya sumber dan fasilitas 
belajar yang dimiliki. Hal ini menyebabkan motivasi belajar mahasiswa menjadi rendah dan tentunya berakibat pada rendahnya penguasaan konsepnya. Oleh karena itu, perlu adanya penerapan metode dan sumber belajar yang tepat. Pemanfaatan Pantai Karangsong sebagai sumber belajar berbasis kearifan lokal diharapkan dapat dijadikan solusi untuk permasalahan tersebut. Selain berakibat pada meningkatnya pemahaman konsep mahasiswa juga sekaligus dapat mengenalkan kearifan lokal yang dimiliki oleh Kabupaten Indramayu. Sehingga Pantai Karangsong Indramayu akan semakin dikenal tidak hanya di daerahnya sendiri.

\section{METODE}

Metode yang digunakan dalam penelitian ini adalah metode campuran atau mix method. Penelitian metode campuran menurut Creswell (2014) yaitu pendekatan penelitian yang mengombinasikan atau mengasosiasikan bentuk kualitatif dan bentuk kuantitatif. Strategi yang digunakan pada penelitian ini yaitu strategi eksplanatoris sekuensial. Penelitian ini dilakukan di STKIP NU Indramayu pada perkuliahan Program Studi PGSD khususnya pada mata pelajaran Konsep Dasar Biologi di SD. Penelitian ini dilakukan pada semester genap tahun pembelajaran 2017/2018.

Teknik pengumpulan data kualitatif menggunakan data tes. Pengumpulan data tes dimaksudkan untuk mengetahui pemahaman konsep sebelum (pretest) dan setelah (posttest) diberikan perlakukan. Tes berupa soal evaluasi dalam bentuk uraian yang digunakan untuk mengetahui peningkatan pemahaman konsep mahasiswa PGSD STKIP NU Indramayu. Analisis data kuantitatif dilakukan dengan cara melakukan uji $\mathrm{N}$-Gain. Uji $\mathrm{N}$-Gain digunakan untuk mengetahui peningkatan pemahaman konsep sebelum dan sesudah dilakukan perlakuan.

Teknik pengumpulan data kualitatif dilakukan dengan wawancara. Wawancara dilakukan oleh peneliti kepada mahasiswa untuk mendapatkan data kualitatif mengenai hambatan mahasiswa dalam meningkatkan pemahaman konsep berikut dengan solusinya. Wawancara dilakukan menggunakan alat perekam suara. Narasumber ditentukan dengan cara snowball sampling. Analisis data kualitatif pada penelitian ini untuk mendeskripsikan hambatan mahasiswa dalam meningkatkan pemahaman konsep keanekaragaman hayati sekaligus memberikan solusinya. Menurut Sugiyono (2010) ada tiga langkah analisis data kualitatif yaitu reduksi data, penyajian data, menarik kesimpulan atau verifikasi.

\section{HASIL DAN PEMBAHASAN}

\section{Hasil}

1. Hasil Analisis Tes Hasil Belajar

Peningkatan hasil belajar mahasiswa PGSD STKIP NU Indramayu diuji dengan menggunakan $\mathrm{N}$-Gain yaitu berdasarkan selisih dari pretest dan posttest mahasiswa PGSD. Hasil analisis uji peningkatan hasil belajar dapat dilihat pada tabel 1.

Peningkatan hasil belajar dengan menggunakan uji $N$-Gain berdasarkan tabel 1 . dengan rata-rata pretest sebesar 30,91 menjadi 81,21 pada rata-rata posttest memperlihatkan adanya peningkatan hasil belajar mahasiswa PGSD STKIP NU Indramayu setelah pembelajaran dengan memanfaatkan Pantai Karangsong sebagai sumber belajar berbasis kearifan lokal yaitu diketahui dari $N$-Gain sebesar 0,81 dengan kategori tinggi. 
Formatif: Jurnal Ilmiah Pendidikan MIPA

Vol. 8, No. 3, Desember 2018, pp. 185-192

p-ISSN: 2088-351X

e-ISSN: 2502-5457

DOI: http://dx.doi.org/10.30998/formatif.v8i3.2930

Tabel 1. Rekapitulasi Peningkatan Hasil Belajar Mahasiswa PGSD

\begin{tabular}{lcccc}
\hline & Pretest & Pottest & N-Gain & Kategori \\
\hline Total & 1020 & 2680 & & \\
Nilai Rata-Tata & 30,91 & 81,21 & 0,81 & Tinggi \\
Minimum & 23 & 70 & & \\
Maksimum & 40 & 97 & & \\
\hline
\end{tabular}

2. Kendala yang Dihadapi Mahasiswa dalam Pemanfaatan Pantai Karangsong sebagai Sumber Belajar Berbasis Kearifan Lokal

Analisis kendala yang dihadapi mahasiswa PGSD dalam pemanfaatan pantai karangsong sebagai sumber belajar didapat dari data kuantitatif yaitu hasil pretest dan posttest mahasiswa PGSD dan dari data kualitatif yaitu hasil analisis wawancara setelah pembelajaran berakhir. Berdasarkan sumber data tersebut, maka kendala yang dihadapi mahasiswa PGSD dalam pemanfaatan Pantai Karangsong sebagai sumber belajar dibagi menjadi dua faktor yaitu sebagai berikut.

a. Faktor internal

1) Kurangnya pemahaman mahasiswa tentang flora dan fauna yang ada di Pantai Karangsong.

2) Kurangnya kemampuan mahasiswa dalam menganalisis.

3) Keterbatasan kemampuan mahasiswa dalam melakukan observasi karena sebagian besar mahasiswa tidak terbiasa melakukan kegiatan praktikum.

b. Faktor eksternal

1) Flora dan fauna kurang bervariatif karena lokasi tidak terlalu luas.

2) Keseimbangan ekosistem di Pantai Karangsong terganggu karena menjadi objek wisata.

3) Keterbatasan alat untuk mengamati objek penelitian mengakibatkan kurangnya informasi yang diperoleh oleh mahasiswa.

4) Belum adanya penerapan model pembelajaran yang tepat.

3. Solusi dari Kendala yang Dihadapi Mahasiswa dalam Pemanfaatan Pantai

Karangsong sebagai Sumber Belajar Berbasis Kearifan Lokal

Berdasarkan hasil dari analisis faktor kendala yang dihadapi mahasiswa PGSD dan berdasarkan dari hasil analisis wawancara mahasiswa PGSD, maka solusi dari kendala yang dihadapi mahasiswa dalam pemanfaatan Pantai Karangsong sebagai sumber belajar yaitu sebagai berikut.

a. Faktor internal

1) Diadakan pendalaman materi mengenai flora dan fauna yang ada di Pantai Karangsong.

2) Diadakan latihan-latihan yang dapat mengembangkan kemampuan analisis mahasiswa.

3) Merancang pembelajaran yang dapat melatih kemampuan observasi mahasiswa.

b. Faktor eksternal

1) Memberikan usulan kepada pemerintah daerah untuk memperluas wilayah hutan mangrove yang ada di Pantai Karangsong.

2) Mengajak mahasiswa untuk menjaga keseimbangan ekosistem di Pantai Karangsong.

3) Pengadaan alat-alat yang dapat mendukung pembelajaran outdoor khususnya di Pantai Karangsong. 
Formatif: Jurnal Ilmiah Pendidikan MIPA

Vol. 8, No. 3, Desember 2018, pp. 185-192

p-ISSN: 2088-351X

e-ISSN: 2502-5457

DOI: http://dx.doi.org/10.30998/formatif.v8i3.2930

4) Adanya penerapan model pembelajaran yang sesuai, sehingga tujuan pembelajaran akan tercapai.

\section{Pembahasan}

1. Hasil Analisis Tes Hasil Belajar

Pemanfaatan Pantai Karangsong sebagai sumber belajar berbasis kearifan lokal berdasarkan tabel 1 terbukti dapat meningkatkan hasil belajar mahasiswa PGSD STKIP NU Indramayu dengan $N$-Gain sebesar 0,81 dengan kategori tinggi. Pembelajaran dengan memanfaatkan lingkungan sebagai sumber belajar dapat meningkatkan minat mahasiswa dalam mengikuti pembelajaran karena pemanfaatan Pantai Karangsong sebagai sumber belajar dapat memberikan pengalaman belajar secara langsung dan konkret. Pembelajaran akan lebih menyenangkan dan mampu menstimulus rasa ingin tahu mahasiswa mengenai hal-hal baru yang ditemui di alam sehingga mahasiswa dapat mengembangkan pengetahuan yang dimilikinya.

Pada penelitian lain yang dilakukan oleh Pantiwati (2015), pembelajaran dengan memanfaatkan lingkungan sebagai sumber belajar bahkan dapat meningkatkan kesadaran metakognitif peserta didik sehingga muncul keterampilan strategi metakognitif untuk mengembangkan diri bahkan mengembangkan lembaga.

Pemanfaatan lingkungan sebagai sumber belajar pada penelitian yang dilakukan oleh Hendarwati (2013) ditemukan bahwa aktivitas siswa dalam pembelajaran IPS dengan memanfaatkan lingkungan sebagai sumber belajar melalui metode inkuiri dalam proses pembelajaran IPS dapat merangsang siswa, ditunjukkan oleh antusias dan keceriaannya dalam mengikuti kegiatan pembelajaran IPS, memiliki keberanian membuat pertanyaan atau jawaban serta mampu berpikir kritis, analitis, dan argumentatif. Hal tersebut tampak dari aktivitas siswa dalam mengemukakan pendapatnya ketika menjawab pertanyaan secara berkelompok. Hasil belajar siswa pada mata pelajaran IPS dengan memanfaatkan lingkungan sebagai sumber belajar dengan menggunakan metode inkuiri lebih baik daripada pembelajaran dengan metode ceramah.

Di samping itu pemanfaatan Pantai Karangsong sebagai sumber belajar dapat melatih sikap keterampilan bekerja sama dalam memecahkan suatu permasalahan. Mahasiswa juga dirangsang untuk meningkatkan keterampilan berpikir, seperti mengobservasi, mengidentifikasi, menganalisis, dan membuat kesimpulan dari hasil observasi yang telah dilakukan. Pemanfaatan sumber belajar berbasis kearifan lokal juga dapat menambah wawasan mahasiswa mengenai sumber daya alam yang ada di daerah mahasiswa itu tinggal, sehingga mahasiswa diharapkan dapat lebih baik memanfaatkan dan menjaga kekayaan alam yang ada di daerah tersebut.

2. Kendala yang Dihadapi Mahasiswa dalam Pemanfaatan Pantai Karangsong sebagai Sumber Belajar Berbasis Kearifan Lokal

Berdasarkan analisis hasil belajar dan wawancara yang dilakukan pada mahasiswa Prodi PGSD, maka kendala yang banyak dimiliki mahasiswa yaitu mengenai kurangnya pemahaman mahasiswa tentang flora dan fauna yang ada di Pantai Karangsong, kurangnya kemampuan mahasiswa dalam menganalisis, dan keterbatasan kemampuan mahasiswa dalam melakukan observasi.

Keterbatasan tersebut diakibatkan karena mahasiswa tidak terbiasa melakukan pembelajaran yang membutuhkan keterampilan mengobservasi dan menganalisis seperti kegiatan praktikum, percobaan atau pembelajaran outdoor yang melibatkan keterampilan proses sains, sehingga mahasiswa kurang terlatih dalam melakukan analisis dan melakukan kegiatan observasi. 
Penemuan serupa juga dikemukakan oleh Glancy et al (2017) dalam penelitiannya yang mengungkapkan bahwa kegiatan menganalisis data memiliki banyak karakteristik yang diidentifikasi sebagai kontribusi kemampuan siswa untuk mengembangkan keterampilan dalam pembuatan analisis data. Namun siswa masih mengalami kesulitan yang cukup besar untuk melakukan analisis data. Seperti kesulitan dalam melakukan pengukuran dan kesulitan menggunakan alat pengukur, sulit bagi siswa untuk menafsirkan data yang diperoleh dari hasil pengukuran.

Faktor eksternal yang menjadi kendala yaitu Pantai Karangsong yang dijadikan sebagai objek wisata mengakibatkan keseimbangan ekosistem di Pantai Karangsong terganggu, akibatnya banyak flora dan fauna yang ditemukan telah rusak dan mati akibat gangguan manusia. Di samping itu, flora dan fauna yang ada di Pantai Karangsong kurang bervariasi karena lokasi tidak terlalu luas sehingga mempengaruhi hasil temuan mahasiswa mengenai flora dan fauna yang ada di Pantai Karangsong. Hambatan lain juga mengenai masalah keterbatasan alat untuk mengamati objek penelitian sehingga mengakibatkan kurangnya informasi yang diperoleh oleh mahasiswa.

Menurut Sanjaya (dalam Prastowo, 2018) sumber belajar berkaitan dengan segala sesuatu yang memungkinkan siswa dapat memperoleh pengalaman belajar. Di dalamnya meliputi lingkungan fisik seperti tempat belajar, bahan dan alat yang dapat digunakan. Berdasarkan pendapat tersebut, alat dalam suatu pembelajaran merupakan salah satu faktor pendukung keberhasilan suatu pembelajaran.

3. Solusi dari Kendala yang Dihadapi Mahasiswa dalam Pemanfaatan Pantai Karangsong sebagai Sumber Belajar Berbasis Kearifan Lokal

Solusi yang dapat dilakukan untuk menyelesaikan masalah pembelajaran dalam pemanfaatan Pantai Karangsong sebagai sumber belajar yaitu dengan cara mengadakan pendalaman materi mengenai flora dan fauna yang ada di Pantai Karangsong. Salah satunya dengan melibatkan petugas Pantai Karangsong sebagai tour guide untuk menunjukkan dan menjelaskan jenis flora dan fauna yang ada di Pantai Karangsong sehingga mahasiswa dapat lebih mendalami materi yang terkait dengan flora dan fauna.

Untuk menyelesaikan kendala mahasiswa mengenai kemampuan analisis dan mengobservasi, salah satunya dengan merencanakan pembelajaran yang dapat melatih kemampuan mengobservasi dan mengadakan latihan yang dapat mengembangkan kemampuan analisis mahasiswa.

Pemilihan metode dan model pembelajaran yang sesuai dengan kebutuhan mahasiswa dan sesuai dengan lingkungan sumber belajar merupakan salah satu faktor keberhasilan dalam pembelajaran. Penggunaan model pembelajaran inkuiri terbimbing merupakan salah satu cara untuk dapat meningkatkan keterampilan menganalisis dan mengobservasi mahasiswa. Berdasarkan penelitian yang dilakukan oleh Seranica et al (2018) mengungkapkan bahwa model pembelajaran inkuiri terbimbing memiliki kelebihan dibandingkan dengan model pembelajaran konvensional dalam hal mengembangkan keterampilan berpikir kritis dengan salah satu indikatornya yaitu menganalisis dan mengobservasi. Dalam pembelajaran inkuiri terbimbing, siswa akan terlibat langsung dalam pembelajaran, selalu dilatih untuk menyelesaikan masalah yang berkaitan dengan lingkungan.

Solusi untuk kendala yang dihadapi mahasiswa dalam pemanfaatan Pantai Karangsong yaitu dengan memberikan usulan kepada pemerintah daerah untuk memperluas wilayah hutan mangrove yang ada di Pantai Karangsong. Mengajak mahasiswa untuk menjaga keseimbangan ekosistem di Pantai Karangsong dengan cara penanaman mangrove, menjaga flora dan fauna, juga menjaga kebersihan Pantai Karangsong. Selain itu juga dengan mengadakan kegiatan bakti sosial di Pantai 
Karangsong dan pengadaan alat-alat yang dapat mendukung pembelajaran outdoor khususnya di Pantai Karangsong.

\section{PENUTUP}

Berdasarkan hasil penelitian diperoleh kesimpulan sebagai berikut:

Pemanfaatan Pantai Karangsong sebagai sumber belajar berbasis kearifan lokal dapat meningkatkan pemahaman konsep makhluk hidup dan lingkungannya pada mahasiswa Pendidikan Guru Sekolah Dasar STKIP NU Indramayu dengan perolehan nilai $N$-Gain sebesar 0,81 dengan kategori tinggi. Hambatan yang dialami oleh mahasiswa Pendidikan Guru Sekolah Dasar STKIP NU Indramayu dalam memanfaatkan Pantai Karangsong sebagai sumber belajar berbasis kearifan lokal adalah kurangnya pemahaman mahasiswa tentang flora dan fauna yang ada di Pantai Karangsong, kurangnya kemampuan mahasiswa dalam menganalisis, keterbatasan kemampuan mahasiswa dalam melakukan observasi, flora dan fauna yang ada di Pantai Karangsong kurang bervariatif, terganggunya keseimbangan ekosistem karena dijadikan sebagai objek wisata, terbatasnya alat untuk mengamati objek penelitian dan belum adanya penerapan model pembelajaran yang tepat.

Solusi yang dapat dilakukan untuk mengatasi kendala mahasiswa dalam memanfaatkan Pantai Karangsong sebagai sumber belajar berbasis kearifan lokal adalah diadakan pendalaman materi mengenai flora dan fauna yang ada di Pantai Karangsong, merancang pembelajaran yang dapat melatih kemampuan mahasiswa dalam mengobservasi dan menganalisis, memberikan usulan kepada pemerintah daerah untuk memperluas area hutan mangrove, mengajak mahasiswa untuk menjaga keseimbangan ekosistem di Pantai Karangsong, pengadaan alat-alat yang dapat mendukung pembelajaran outdoor khususnya di Pantai Karangsong, dan menerapkan model pembelajaran yang sesuai sehingga tujuan pembelajaran akan tercapai.

\section{DAFTAR PUSTAKA}

Creswell, J.W. (2014). Research Design - Pendekatan Kualitatif, Kuantitatif, dan Mixed. Terjemah Achmad Fawaid. Yogyakarta: Pustaka Pelajar.

Hendarwati, E. (2013). Pengaruh pemanfaatan lingkungan sebagai sumber belajar melalui metode inkuiri terhadap hasil belajar siswa SDN I Sribit Delanggu pada pelajaran IPS. Pedagodia, 2(1):59-70.

Glancy, Aran N., Moore, Tamara J., Guzey, Selcen., \& Smith, Karl A. (2017). Students' successes and challenges applying data analysis and measurement skills in a fifthgrade integrated STEM unit. Journal of Pre-College Engineering Education Research (J-PEER), 7(1):68-75.

Leonard. (2018). Task and forced instructional strategy: instructional strategy based on character and culture of Indonesia nation. Formatif: Jurnal Ilmiah Pendidikan MIPA, 8 (1): 51-56. http://dx.doi.org/10.30998/formatif.v8i1.2408

Pantiwati, Y. (2015). Pemanfaatan lingkungan sekolah sebagai sumber belajar dalam lesson study untuk meningkatkan metakognitif. Bioedukatika, 3(1):27-32. http://journal.uad.ac.id/index.php/BIOEDUKATIKA/article/view/4144.

Prasetyo, Z.K. (2013). Pembelajaran Sains Berbasis Kearifan Lokal. Prosiding Seminar Nasional Fisika dan Pendidikan Fisika UNY, 1-14. Yogyakarta: Pascasarjana UNY. 
Formatif: Jurnal Ilmiah Pendidikan MIPA

Vol. 8, No. 3, Desember 2018, pp. 185-192

p-ISSN: 2088-351X

e-ISSN: 2502-5457

DOI: http://dx.doi.org/10.30998/formatif.v8i3.2930

Prastowo, A. (2018). Sumber Belajar dan Pusat Sumber Belajar Teori dan Aplikasinya di Sekolah/Madrasah. Depok: Prenadamedia Group.

Seranica, Christinsenia., Purwoko, Agus Abi., \& Hakim, Aliefman. (2018). Influence of guided inquiry learning model to critical thinking skills. IOSR Journal of Research \& Method in Education (IOSR-JRME), 8(1): 28-31.

Sugiyono. 2010. Metode Penelitian Pendidikan Pendekatan Kuantitatif, Kualitatif, dan $R \& D$. Bandung: Alfabeta. 